\title{
Clinical and Laboratory Presentations of Leptospirosis Patients in North of Iran
}

\author{
Mostafa Javanian ${ }^{1}$, Masomeh Bayani ${ }^{1}$, Moharam Esfandiar ${ }^{1}$, Arefeh Babazadeh ${ }^{1} \&$ Soheil Ebrahimpour ${ }^{1}$ \\ ${ }^{1}$ Infectious Diseases and Tropical Medicine Research Center, Health Research Institute, Babol University of \\ Medical Sciences, Babol, I.R. Iran \\ Correspondence: Masomeh Bayani, Infectious Diseases and Tropical Medicine Research Center, Health Research \\ Institute, Babol University of Medical Sciences, Babol, I.R. Iran. Tel: 98-911-311-2559. Email: \\ m_baiany@yahoo.com
}

Received: August 22, 2017

doi:10.5539/jmbr.v7n1p122
Accepted: September 12, $2017 \quad$ Online Published: September 18, 2017

URL: https://doi.org/10.5539/jmbr.v7n1p122

\begin{abstract}
Leptospirosis is a zoonosis that common in warm and tropical regions with global spread and it is an occupational disease. The aim of recent study was to evaluate the clinical and Para clinical findings of leptospirosis patients in Babol, northern of Iran. In this cross-sectional study, 118 patients with high suspicion to leptospirosis admitted to hospitals of Babol University of Medical Sciences, Babol, Iran, during 2009 -2011. Thirty one cases with positive finding (IFA) were enrolled as definitive Patients. Clinical and Para clinical data for all patients were recorded. The mean age of the confirmed patients (male: $71 \%$, rural: $90.5 \%$ ) was 48.5 years (range 18-80 years old). The commonest chief complaints were fever (71\%) and ichter $(19 \%)$ and among the clinical features of them fever (90.5\%), gastro intestinal signs $(80.5 \%)$, ichter $(71 \%)$ and headache $(68 \%)$ was the most prevalent ones. Weil's syndrome occurred in $10(32 \%)$ patients. Thrombocytopenia and leukocytosis were noticed in $80.5 \%$ and $42 \%$ of the patients respectively. Transaminases in $80.5 \%$ of cases were above the normal upper limit. Based on current study, the most of leptospirosis patients were farmers and presented in hot seasons. The commonest clinical and laboratory pattern of this disease in our region was fever, ichter, myalgia and headache in conjunction with Mild elevations in levels of transaminases and thrombocytopenia that can be used as a good marker in early clinical diagnosis and treatment.
\end{abstract}

Keywords: leptospirosis, zoonosis, clinical and laboratory findings, thrombocytopenia

\section{Introduction}

Leptospirosis is a zoonosis disease with global spread that is created by pathogenic spirochete of leptospira type which is the most common zoonoses (Barragan et al., 2016). This disease is more common in hot and tropical areas and remains in the nature through chronic renal infection of carrier animal especially, rodents and small mammals that shed it with their urine; human infection occurs with direct contact to the urine or infected tissue of carrier animals, or as a more common way, with indirect exposure to the organism in wet soil or contaminated water (Kue et al., 2003; Mandell, 2015). It is regarding as an occupational disease in developing country and in developed one, it is related to the recreational activity related to water (Mandell, 2015). Although this infection is potentially a fatal disease along with bleeding manifestation and multi- organ failure, in the most symptomatic cases it is mild and is a febrile illness with sudden onset. Its incubation period is from one to two weeks (1-30 days interval) and clinically, it is a two - phase disease, including:

1) Acute leptospiromic phase along with presentations such as fever, headache and myalgia.

2) The second phase is an immunologic phase and one of its presentation is Weil's syndrome that is the most acute form of the disease along with icterus, renal dysfunction and hemorrhagic manifestations and in many cases, pulmonary involvement (Kasper et al., 2016; Trueba et al., 2004). The mortality resulted from this illness was ranged from 1 to $54 \%$ in different studies (Yamashita et al., 2010). The most reported cases in Iran were from Northern provinces such as Guilan province that has occurred epidemically among farmers since 1998( Abdollahpour et al.,2011; Mansour-Ghanaei et al., 2005; Zakeri et al., 2010).

After 2003, the reported cases in Mazandaran province were from rural area, especially in rice planting seasons (spring) (Babamahmoodi et al., 2009). Regarding the epidemiologic properties of Mazandaran province and 
common agricultural occupations among people, this province is considering as an endemic area for this illness (Babamahmoodi et al., 2006; Kasper et al., 2016).

Whereas it is necessary to know the common clinical and laboratorial patterns of the disease to start the effective and timely treatment, we decided to achieve the dominant pattern of this disease through the investigation of these cases.

\section{Materials and Methods}

This study was performed in a cross- sectional method. Patients who were suspicion of the leptospirosis, based on the description, clinical and laboratorial symptoms from April of 2009 to the September of 2010, were hospitalized. There were a range of symptoms such as headache, myalgia, jaundice, conjunctival hyperemia along with laboratorial findings including, thrombocytopenia and increasing in transaminases. Although MAT method is a standard serologic testing for leptospirosis diagnosis and has more sensitivity than our method, but because of standardization of IFA comparing to MAT, and not requiring any organism, availability, faster performance time and lower cost, this method was selected as a serologic diagnostic test and the measures more than or equals to 0.1 have considered positive. Also, IFA has $95.5 \%$ specificity comparing to MAT (Esmaeili et al., 2009; Mandell, 2015).

For this purpose, 118 suspicious patients went under the venous blood sampling equals to $5 \mathrm{ml}$ to perform serologic investigation and the samples transferred to the laboratory by observing the cold chain. Thirty one patients had IFA result more than or equals to 0.1 among them. The investigation of clinical and laboratorial symptoms and epidemiologic background have been done in these definite patients. In addition, patients went under the treatment by Ceftriaxone (61\%), Ampicillin (19.5\%). The current study protocol was approved by ethics committee of Babol University of Medical Sciences. All cases signed written informed consent form.

\subsection{Data Analysis}

The resulted information was entered into some questionnaires and after classification; the questionnaires were analyzed by SPSS16 software.

\section{Results}

Thirty one out of 118 patients with suspicion of leptospirosis had positive serology that entered to the study and the clinical and laboratorial findings of them have been investigated. Most cases admitted in June (35.5\%) and then September (22.5\%). Most patients with such a diagnosis were rural people $(90.5 \%)$ and males $(71 \%)$. The average time of hospitalization was 8.3 days. The age interval of the patients were varying from 18 to 80 years that most of them were in age group more than or equals to 50. The main complaint of most patients was fever (71\%) and then Jaundice (19\%). Also, in surveying of common clinical symptoms, $90.5 \%$ of the patients had fever that 11 of them had body temperature over 39 degree Celsius. In younger age groups appearing fever was higher, after that gastrointestinal symptoms with $(80.5 \%)$ and then icterus with $71 \%$, were the most common symptoms; icterus was also higher in older age (Table1).

Table 1. Clinical findings in leptospirosis patients

\begin{tabular}{lll}
\hline Clinical finding & Frequency & Percent \\
\hline Fever & 28 & 90.3 \\
Gastrointestinal symptoms & 25 & 80.6 \\
Ichter & 22 & 71 \\
Headache & 21 & 67.7 \\
Urinary symptoms & 20 & 64.5 \\
myalgia & 17 & 54.8 \\
Weakness & 17 & 54.8 \\
Abdominal pain & 15 & 48.4 \\
Conjunctival hyperemia & 11 & 35.5 \\
Cough & 8 & 25.8 \\
Joint's pain & 6 & 19.4 \\
Rash & 3 & 0.1 \\
\hline
\end{tabular}

In epidemiologic investigation of these patients, the most common risk factor was work experience in the rice farms. In examining the laboratorial findings of the patients the amount of white blood cells were varying from $3100 / \mathrm{m}$ to $24400 / \mathrm{m}$ that in all cases polynuclears were dominant. Leukopenia was only in $3.2 \%$ and leukocytosis 
in $42 \%$ of the patients. $80.5 \%$ of the patients had thrombocytopenia that we had also up to $6100 / \mathrm{m}$ decrease in platelet. Creatinine increasing only was seen in $26 \%$ and coagulopathy only in $9.5 \%$. Increase in transaminases was seen in $80.5 \%$ which were higher than $200 \mathrm{U} / \mathrm{L}$ only in 3 individuals. In icterus case, Hyperbilirubinemia was observed in $71 \%$ that $32 \%$ of the patients admitted with Weil's syndrome manifestations (Table2). From 28 Febrile patients, 26 cases' fever stopped in the first week after the symptoms and in all cases after starting antibiotic treatment. In addition, in following the treatment results of thrombocytopenia and liver and kidney enzymes disorders, the patients had complete recovery and there was only one case of fatality.

Table 2. Laboratory findings in leptospirosis patients

\begin{tabular}{|c|c|c|c|}
\hline Laboratory findings & & Frequency & Percent \\
\hline \multirow[t]{2}{*}{ WBC } & $<4000 \mathrm{Cell} / \mathrm{mm} 3$ & 1 & 3.2 \\
\hline & $>10000 \mathrm{Cell} / \mathrm{mm} 3$ & 13 & 13.42 \\
\hline $\mathrm{Hb}<12 \mathrm{gr} / \mathrm{dl}$ & & 16 & 52 \\
\hline PLT $<150000 \mathrm{cell} / \mathrm{mm} 3$ & & 25 & 80.5 \\
\hline BUN $>20 \mathrm{mg} / \mathrm{dl}$ & & 16 & 52 \\
\hline $\mathrm{Cr}>1.5 \mathrm{mg} / \mathrm{dl}$ & & 8 & 26 \\
\hline $\mathbf{A L T}>35 \mathrm{U} / \mathbf{L}$ & & 25 & 80.5 \\
\hline $\mathbf{A S T}>35 \mathrm{U} / \mathrm{L}$ & & 26 & 84 \\
\hline $\mathbf{A L P}>\mathbf{3 0 0} \mathbf{U} / \mathbf{L}$ & & 14 & 46 \\
\hline \multirow[t]{2}{*}{ Bil } & Total $>1 \mathrm{mg} / \mathrm{dl}$ & 22 & 71 \\
\hline & Direct $>0.4 \mathrm{mg} / \mathrm{dl}$ & 19 & 61.5 \\
\hline PT $>14$ sec & & 3 & 9.5 \\
\hline PTT $>45 \mathrm{sec}$ & & 3 & 9.5 \\
\hline
\end{tabular}

\section{Discussion}

Among 31 definite patients which were examined in our study, most of them were males and rural people. The background of working in rice farm was the most common risk factor related to the infection. In other performed study in Mazandaran and Guilan province also, farmers were infected to this disease more than other occupations (Esmaeili et al., 2009; Mansour-Ghanaei et al., 2005). Due to the more engagement of males to the agriculture, it is expected that the infection be higher among them. The mean age of the infected people in this study was 48.5 that is similar to some of the conducted study in north of Iran ( Esmaeili et al., 2009). This can be due to the sociological condition of our area that the elderly are more engaged in the agriculture, and the lower tendency of youths to this occupation caused the increase in the age average of the farmers. In addition, our study was performed on the hospitalized patients, and regarding to the weaker immune system of elderlies, the probability of hospitalization is higher among them, although some studies have shown lower average age of infection (Sethi et al., 2010).

In current study, we observed increasing admissions of the patients in June and regarding the work in rice farms as a risk factor, the high frequency in this month is justifiable. Furthermore, similar to several other studies, fever was the most common symptom of this disease in our area (Daher et al., 2010; Katz et al., 2011; Mansour-Ghanaei et al., 2005; Papa et al., 2009). Fever in the age under 40 was higher (100\%) that is justifiable, because of weaker infection manifestations in elderly. Manifestations of icterus, myalgia and fatigue in ages over 50 were higher $(80 \%$ comparing to $50 \%$ in the ages under 40 ) and by increasing the age, the emergence of icterus was increased. The most common laboratorial finding of the present study, like other studies, was the increasing of transaminases, but in different studies and also in text books it is mentioned that this disease creates a slight increase in transaminases( maximum $200 \mathrm{U} / \mathrm{L}$ )(Kasper et al., 2016; Sethi et al., 2010). But in our study, in three cases and in a study from India in two cases out of 86, there were abnormal increase in transaminases (over 200U/L), that regarding to the rejection of the other causes of increase in transaminases and the diseases along with, such as viral hepatitis, it can be attributable to the leptospirosis, it means that the 200U/L cut point is not absolute for this disease ( Sethi et al., 2010). In next stage of the outbreak of laboratorial symptoms there was thrombocytopenia with $80.5 \%$ frequency that was similar to the studies in Guilan; in contrast, in the studies of other areas of the world, appearing this disease with para clinical sign has been less than our study (Daher et al., 2010; Katz et al., 2011; MansourGhanaei et al., 2005). So, this common finding can be used in diagnosis of leptospirosis patients in this area. In current study, most of the patients had normal leukocyte but $3.2 \%$ of leukopenia and $42 \%$ of leukocytosis. In another study in Guilan, 78\% of the patients and in Brazil, 69.8\% of them had leukocytosis (Daher et al., 2010; 
Mansour-Ghanaei et al., 2005). From this finding, also, we can reach to this understanding that in patients with such a diagnosis, leukopenia is not expected. Frequency of Weil's syndrome in our study was more than other studies (32\%) that can be because of our study that just examined the hospitalized patients and didn't include the milder one, with outpatient treatment (Jansen et al., 2005; Waitkins, 1986). The fever of all hospitalized patients stopped maximally 2 days after starting the treatment, that it was expectable regarding the inherent sensitiveness of this microorganism to the antibiotic of the first line of its treatment, since the discovery of this bacterium. Therefore, in case of nonstop fever after 48 hours from the beginning of antibiotic, the side effects resulted from the disease and another diagnosis should be regarded. The mortality obtained from our study was $3.2 \%$; this patient was 71years old that admitted with Weil's syndrome manifestations. In different studies mortality is reported around 1 to 50\% (Costa et al., 2015; Hagan et al., 2013; Yamashita et al., 2010). In future studies, it is better to investigate the relationship between the kind of the treatment and the consequence of the disease, and the effect of using preventive antibiotics on at risk people in the common seasons of the disease.

\section{Conclusion}

Considering the epidemiologic pattern of our area, leptospirosis has the most manifestations in rice planting seasons (spring and especially in June) and in male farmers. The common clinical symptoms of this infection include, fever, myalgia, icterus and headache along with slight increase in aminotransferases, Hyperbilirubinemia thrombocytopenia and the leukocyte range of normal to increased, that can have an effective help in more careful detection of the patients, apart from the serologic results. The serological investigation of the received samples at the first week of appearing the disease and after starting antibiotic, often have the false negative results, and the recognition of this pattern is effective for timely detection and treatment of the disease.

\section{Acknowledgments}

Hereby, this is appreciated the deputy of research and technology of Babol University of Medical Sciences for supporting of this research and the staffs of Ayatollah Rouhani and Shahid Yahyanejad Hospitals for their cooperation.

\section{Conflict of interest}

None declared.

\section{References}

Abdollahpour, G., Shafighi, S. T., \& Sattari TAbrizi, S. (2009). Serodiagnosis of leptospirosis in cattle in north of Iran, Gilan. Iranian Journal of Veterinary Medicine, 3(1).

Babamahmoodi, F., Motamed, N., \& Ghavibonie Kh, N. F. (2006). epidemiology of leptospirosis in rural area of Ghaemshahr city-Mazandaran province. Journal of Mazandaran University of Medical Sciences, 16(53), 5156.

Babamahmoodi, F., Salmani Mojaveri, M., \& Babamahmoodi, A. (2009). Seroepidemiology of leptospirosis in workers of high risk occupation in Mazandaran province-Iran 2007-2008. Journal of Mazandaran University of Medical Sciences, 19(73), 10-15.

Barragan, V., Chiriboga, J., Miller, E., Olivas, S., Birdsell, D., Hepp, C., ... Gonzalez, M. (2016). High leptospira diversity in animals and humans complicates the search for common reservoirs of human disease in rural Ecuador. PLoS neglected tropical diseases, 10(9), e0004990. https://doi.org/10.1371/journal.pntd.0004990

Costa, F., Hagan, J. E., Calcagno, J., Kane, M., Torgerson, P., Martinez-Silveira, M. S., ... Ko, A. I. (2015). Global morbidity and mortality of leptospirosis: a systematic review. PLoS neglected tropical diseases, 9(9), e0003898. https://doi.org/10.1371/journal.pntd.0003898

Daher, E. F., Lima, R. S., Silva Júnior, G. B., Silva, E. C., Karbage, N. N., Kataoka, R. S., ... Libório, A. B. (2010). Clinical presentation of leptospirosis: a retrospective study of 201 patients in a metropolitan city of Brazil. Brazilian Journal of Infectious Diseases, 14(1), 03-10.

Esmaeili, R., Hesamzadeh, A., Alizadeh-Navaei, R., Haghshenas, M., \& Alhani, F. (2009). Incidence of leptospirosis in Mazandaran Province, north of Iran: a one year survey. Pakistan journal of biological sciences, 12(19), 1330-1333.

Hagan, J., Costa, F., Calcagno, J., Kane, M., Torgerson, P., Martinez-Silveira, M., ... Ko, A. (2013). Global morbidity and mortality of leptospirosis: a systematic review. Paper presented at the Scientific meeting of the International Leptospirosis Society. Fukuoka, Japan. 
Honarmand, H., \& Eshraghi, S. (2011). Detection of Leptospires serogroups, which are common causes of human acute leptospirosis in Guilan, Northern Iran. Iranian journal of public health, 40(1), 107.

Jansen, A., Schöneberg, I., Frank, C., Alpers, K., Schneider, T., \& Stark, K. (2005). Leptospirosis in germany, 1962-2003. Emerging infectious diseases, 11(7), 1048. https://doi.org/10.3201/eid1107.041172

Kasper, D. L., Braunwald, E., Fauci, A. S., Hauser, S. L., Longo, D. L., \& Jameson, J. L. (2016). Harrisons manual of medicine: McGraw-Hill Medical Publishing Division.

Katz, A. R., Buchholz, A. E., Hinson, K., Park, S. Y., \& Effler, P. V. (2011). Leptospirosis in hawaii, USA, 19992008. Emerging infectious diseases, 17(2), 221. https://doi.org/10.3201/eid1702.101109

Kue, H., Lin, C., \& Huang, C. (2003). Reversible thick ascending limb disfunction and aseptic meningitis syndrom: early manifestation in two leptospirosis patients. Renal failure, 25(4).

Mandell, L. (2015). Breaking the Book: Print Humanities in the Digital Age: John Wiley \& Sons.

Mansour-Ghanaei, F., Sarshad, A., Fallah, M.-S., Pourhabibi, A., Pourhabibi, K., \& Yousefi-Mashhoor, M. (2005). Leptospirosis in Guilan, a northern province of Iran: assessment of the clinical presentation of 74 cases. Medical science monitor, 11(5), CR219-CR223.

Papa, A., Theoharidou, D., \& Antoniadis, A. (2009). Pulmonary involvement and leptospirosis, Greece. Emerging infectious diseases, 15(5), 834. https://doi.org/10.3201/eid1505.080270

Sethi, S., Sharma, N., Kakkar, N., Taneja, J., Chatterjee, S. S., Banga, S. S., \& Sharma, M. (2010). Increasing trends of leptospirosis in northern India: a clinico-epidemiological study. PLoS neglected tropical diseases, 4(1), e579. https://doi.org/10.1371/journal.pntd.0000579

Trueba, G., Zapata, S., Madrid, K., Cullen, P., \& Haake, D. (2004). Cell aggregation: a mechanism of pathogenic Leptospira to survive in fresh water. International microbiology, 7(1), 35-40.

Waitkins, S. (1986). Leptospirosis as an occupational disease. British Journal of Industrial Medicine, 43(11), 721.

Yamashita, H., Furusu, A., Nishino, T., Obata, Y., Miyazaki, M., Ichinose, H., ... Hirakata, Y. (2010). Two patients who developed leptospirosis-associated acute renal failure within the same season. Internal Medicine, 49(12), 1143-1147.

Zakeri, S., Sepahian, N., Afsharpad, M., Esfandiari, B., Ziapour, P., \& Djadid, N. D. (2010). Molecular epidemiology of leptospirosis in northern Iran by nested polymerase chain reaction/restriction fragment length polymorphism and sequencing methods. The American journal of tropical medicine and hygiene, 82(5), 899-903. https://doi.org/10.4269/ajtmh.2010.09-0721

\section{Copyrights}

Copyright for this article is retained by the author(s), with first publication rights granted to the journal.

This is an open-access article distributed under the terms and conditions of the Creative Commons Attribution license (http://creativecommons.org/licenses/by/4.0/). 